\title{
COMPREHENSION OF SPATIAL METAPHORS AFTER RIGHT HEMISPHERE STROKE: A CASE REPORT
}

\author{
Vanja Kljajevic ${ }^{1,2}$, Milenka Vranes-Grujicic ${ }^{3}$, Katica Raskovic ${ }^{4}$ \\ ${ }^{1}$ University of the Basque Country (UPV/EHU), Vitoria, Spain \\ ${ }^{2}$ IKERBASQUE, Basque Foundation for Science, Bilbao, Spain \\ ${ }^{3}$ Health Center Bar, Montenegro \\ ${ }^{4}$ Health Center Budva, Montenegro
}

\author{
RAZUMEVANJE PROSTORNIH METAFORA \\ NAKON MOŽDANOG UDARA U DESNOJ HEMISFERI: PRIKAZ SLUČAJA \\ Vanja Kljajević1, ${ }^{1,}$, Milenka Vraneš-Grujičić ${ }^{3}$, Katica Rašković ${ }^{4}$ \\ ${ }^{1}$ Univerzitet Baskije, Vitorija, Španija \\ ${ }^{2}$ Ikerbask, Baskijska fondacija za nauku, Bilbao, Španija \\ JZU Dom zdravlja Bar, Crna Gora \\ ${ }^{4}$ JZU Dom zdravlja Budva, Crna Gora
}

Received / Primljen: 26. 07. 2016.

Accepted / Prihvaćen: 16. 12. 2016.

\begin{abstract}
Studying how spatial information interacts with figurative language processing in right-hemisphere $(R H)$ stroke patients is a relatively neglected area of research. The goal of the present case study was to establish whether an ischemic lesion in the right temporo-parietal region causing spatial neglect would affect comprehension of sentence-level spatial metaphors, since some evidence indicates the crucial role of the RH in metaphor processing. The patient under study showed some degree of cognitive impairment (e.g., in spatial and verbal working memory, executive control, visuo-spatial matching skills). However, his comprehension of spatial metaphors was preserved. This case illustrates that RH damage does not necessarily affect comprehension of sentence-level spatial metaphors.
\end{abstract}

Keywords: spatial metaphors, stroke, right hemisphere, temporo-parietal region, allocentric representations, spatial neglect.

\section{SAŽETAK}

Uticaj spacijalnih informacija na razumevanje figurativnog jezika kod pacijanata sa lezijama u desnoj hemisferi usled moždanog udara je nedovoljno istražena tema. S obzirom na to da dosadašnja istraživanja ukazuju na presudnu ulugu desne hemisfere u razumevanju metafora, cilj naše studije bio je da utvrdi da li ishemijska lezija u desnoj temporalno-parijetalnoj oblasti povezana sa spacijalnim neglektom utiče na razmevanje prostornih metafora u rečenici. Pacijent ZG prikazan u ovoj studiji pokazao je deficit prostorne radne memorije, verbalne radne memorije $i$ vizuelno-prostornih odnosa. Međutim, njegovo razmevanje prostornih metafora je očuvano. Ova studija pokazuje da lezije u desnoj hemisferi ne utiču na razumevanje prostornih metafora.

Ključne reči: prostorne metafore, moždani udar, desna hemisfera, temporo-parijetalna oblast, alocentrične reprezentacije, spacijalni neglekt.

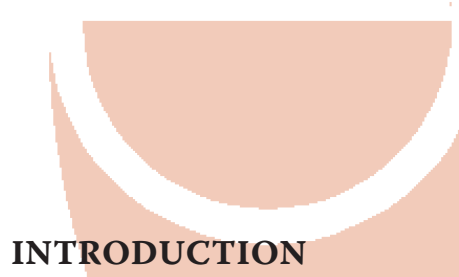

Studying how spatial information interacts with figurative language processing in post-stroke patients is a relatively neglected area of research. While often reported deficits in spatial cognition in Alzheimer's disease (AD) patients are associated with early hippocampal deterioration or with basal forebrain atrophy (1), patterns of deficit/ sparing of spatial processing in post-stroke patients with right hemisphere damage is less clear. Spatial cognition has been associated with a bilateral fronto-parietal network, in which the right hemisphere $(\mathrm{RH})$ plays the main role in directed attention within extrapersonal space $(2,3)$. A hierarchical organization in the processing of spatial relations has been proposed, in which egocentric (body-centered) spatial relations require only a subsystem of the resources required by allocentric (body-independent) spatial relations (4). According to this view, the latter require the $\mathrm{RH}$ involvement. On the other hand, the neural basis of spatial language, e.g. linguistically coded spatial information, involves the left inferior temporal and parietal areas, occipito-temporal junction, inferior prefrontal region and anterior superior temporal gyrus (5-7). However, some evidence suggests that spatial language processing is supported by the brain regions that support non-linguistic spatial processing (8).

It has been debated whether comprehension of metaphors and other types of figurative language requires $\mathrm{RH}$ 
support (9-11). So far, only a small number of studies investigated comprehension of sentence-level metaphors in post-stroke patients. An early study involving patients with RH injury $(n=22)$ reported that these patients had preserved ability to verbally explain metaphoric sentences, but they were correct only half of the times in picture-metaphor matching (12). Another study investigated comprehension of words, familiar phrases (similar to conventional metaphors), and novel sentences in left-hemisphere (LH) aphasic $(n=28)$ and $\mathrm{RH}$-damaged speakers $(\mathrm{n}=11)$ and reported that the $\mathrm{RH}$-damaged group had impairment in the comprehension of familiar phrases, but not in the comprehension of words or novel sentences (13). The group with LH damage showed the opposite pattern: good comprehension of familiar phrases, but impaired comprehension of novel sentences.

A series of three case studies that investigated the comprehension of moderately familiar sentential metaphors and closely matched literal sentences in post-stroke aphasic patients showed that all three patients had moderately impaired comprehension of metaphors. Crucially, one of the three patients had a $\mathrm{RH}$ lesion, whereas the remaining two were LH-damaged aphasic patients. What sets these cases apart is a differential impairment of metaphoric and literal sentence comprehension. Put differently, these patients exhibited three distinct comprehension patterns: the patient with a $\mathrm{RH}$ injury had impaired comprehension of both metaphoric and literal sentences at a comparable level; one of the two patients with LH damage had impaired comprehension of both types of sentences, but with significantly more impaired comprehension of metaphors, while the other had impaired comprehension of metaphoric sentences but spared comprehension of literal sentences (14). Taken together, this evidence indicates the existence of a variety of patterns in metaphor comprehension in poststroke patients that goes beyond simple dichotomies, such as novelty vs. familiarity, and involves damage to both cerebral hemispheres.

In the present study, we investigated the comprehension of sentence-level spatial metaphors in a RH stroke patient. By "spatial metaphors" we refer to the metaphors containing spatial terms or as previously defined in the literature: "Talking in spatial metaphors means using spatial words to describe nonspatial entities, states, or relationships" (15). Comprehension of spatial metaphors requires information integration based on both linguistically coded spatial information and figurative language, where two previously non-linked concepts are joined in a new meaning. Here we focused on conventional metaphors with spatial terms and wanted to determine whether a $\mathrm{RH}$ post-stroke patient with no apparent aphasia had difficulties comprehending metaphoric sentences containing spatial information. We hypothesized that a stroke lesion affecting the right temporo-parietal region and resulting in spatial neglect would be associated with impaired comprehension of spatial relations in the allocentric frame of reference (object-object); however, comprehension of metaphoric sentences with locative predicates and literal sentences with spatial modifiers would be preserved, because the intact left hemisphere would support these tasks. To test these hypotheses, we designed four experiments (section "Evaluative and experimental tests") and tested a right-handed man who had previously suffered a stroke in the right hemisphere (section "Case presentation").

\section{BACKGROUND}

\section{Case presentation}

A 70-year-old right-handed man, ZG, was admitted to the neurology department due to a sudden weakness of the whole left side of body, confusion, and inability to speak. The patient did not have a history of dementia, other brain diseases, or alcohol/drug abuse. He had been treated for angina pectoris for eight years prior to the incident, but he had not been taking the medication regularly. A CT scan showed an acute right-hemisphere temporo-parietal lesion. Additionally, MRI revealed smaller ischemic lesions in the right basal ganglia and occipital lesions. Nine days later, ZG suffered another stroke, which was caused by occlusion of the right internal carotid artery within the cavernous sinus. There was no evidence of lesions in the left hemisphere. An extracranial Doppler sonogram obtained immediately after the first stroke showed no substantial stenosis in the common carotid artery, external carotid artery and internal carotid artery, although atheromatous changes were present, being in particular prominent at the carotid bifurcation; there were no hemodynamic changes in the vertebral arteries or signs of reverse flow. Furthermore, the Multislice Computed Tomography (MSCT) angiography, which was performed 10 days after the second stroke, showed no pathological changes extracranially, in the common carotid artery, external carotid artery or internal carotid artery. The vertebral arteries showed normal hemodynamics, with sufficient blood velocity. The intracranial segments of the internal carotid artery showed no signs of stenosis. In addition, the MSCT scan showed normal branching of the circle of Willis and no signs of pathology.

The medical records indicate that the two major incidents left the patient with a left-side paresis and spatial neglect, which persisted throughout the chronic stage. In addition, immediately after the incidents, the patient showed language disturbances both in speech production and comprehension. For example, he was not able to talk, except to produce one word, "water", or to respond to the questions asked by the medical staff inquiring about his condition. He was disoriented and could not follow commands. He remained at this verbally nonresponsive, lowlevel consciousness and confused state during the initial part of his stay at the hospital, but his condition had improved by the time he was discharged. 
After leaving the hospital, ZG stayed at a rehabilitation institution for three weeks, where he underwent an intensive program for rehabilitation of motor and cognitive functions. The initial language disturbances were transient and resolved spontaneously, leaving the patient with some reading difficulties (section "Results"). In addition, he exhibited memory problems (forgetfulness, difficulty with retrieval of words and names), but according to his spouse, these were present before the illness. Since leaving the rehabilitation institution, he has continued the intensive physical therapy at home, which he has had four times per week. He has regularly attended neurological followup exams as scheduled and visited his general practitioner for a check-up once a month.

At the time of testing for the present study, which was 4 years post-onset, ZG had left-side hemiparesis, no apparent language disturbances, and was using the following prescribed medications: amiodaron to regulate arrhythmia, plavix to prevent platelets from clumping together and forming blood clots, clonazepam to control muscle spasms, and nitroglycerin for the management of angina pectoris. When asked about his condition, ZG complained that he "cannot see things on the left side". He also stated that he needed more time to complete any mentally engaging task than before the illness and that he now preferred a slower rate of speech in conversation, especially with speakers who use longer and more complex sentences.

Before the testing began, the patient signed informed consent. In addition, five neurologically intact subjects participated in the study as a control group. They also signed informed consent. The study was conducted in accordance with the guidelines of the Declaration of Helsinki for studies involving human subjects.

\section{Evaluative and experimental tests}

In addition to consulting ZG's medical records, before conducting experiments, we administered a set of evaluative tests: an aphasia screening test validated for Serbian (16) to determine patient's language status, Montreal Cognitive Assessment (MoCA) (17) to evaluate his general cognitive status, the Month ordering test (18) to assess his verbal working memory, and Raven's Coloured Progressive Matrices (19) to assess his visuospatial pattern-matching ability and relational reasoning.

Four experiments were designed to test the following abilities of the patient: spatial working memory (Experiment 1), comprehension of basic spatial relations (Experiment 2), use of spatial prepositions in nonfigurative sentences (Experiment 3) and comprehension of sentencelevel metaphors with spatial terms (Experiment 4).

Briefly, Experiment 1 consisted of 40 pairs of symbols that were modified from the Glagolitic alphabet, with which the patient was not familiar. One half of the stimuli contained pairs with two identical symbols and
Table 1. Examples of stimuli for Experiment 1.

The task was to judge whether the second symbol (column 2) of a pair was positioned in the same way or differently from the first symbol (column 1) of that pair. The first three rows in the table illustrate the pairs with differently positioned symbols and the last three rows illustrate the pairs of symbols positioned in the same way.

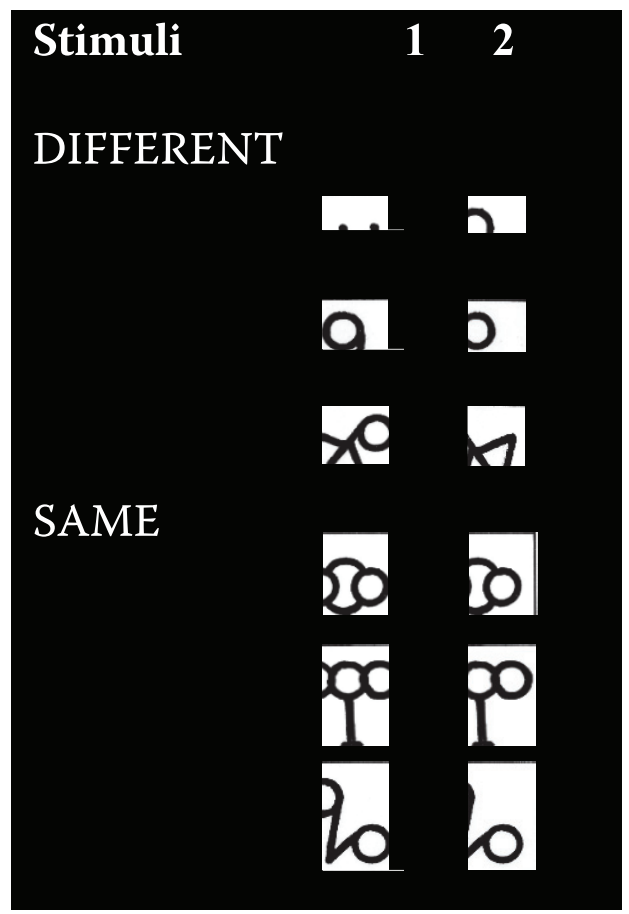

the other half contained pairs with two different symbols. The pairs containing different symbols were created by manipulating one symbol along either a vertical reference axis (up, down) or horizontal reference axis (left, right). Crucially, in a pair with two different symbols, the symbols differed in only one spatial feature, which was varied across the upper vs. lower left vs. right quadrants. In this experiment, the symbols in each pair were presented separately for 3 seconds, with the second symbol immediately following the first one (see Table 1 for examples). The task was to decide whether the second symbol was positioned in the same way or differently from the first symbol, i.e. whether the two express the same spatial relation. The order of presentation of the pairs containing same/different symbols was randomized. The stimuli were printed in black color on a white background and positioned in the center of page. The time to respond was not limited.

Experiment 2 tested participants' ability to identify spatial relations among paired objects in drawings (e.g., heart, cross, circle, triangle, etc.). The stimuli consisted of 14 pairs of drawn objects, each testing a different spatial relation in the object-object frame of reference, such as behind, in front of, on top of, below. Each pair was presented on a separate sheet of paper, and above each pair a written word indicated the target spatial relation, e.g., "BELOW". The task was to form a sentence expressing the spatial relation between the presented pair of objects based on that 
1

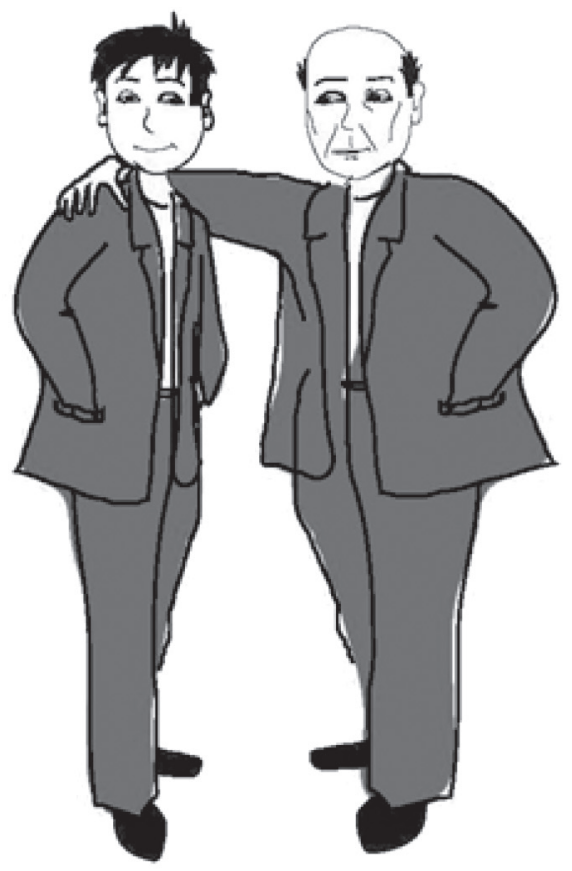

2

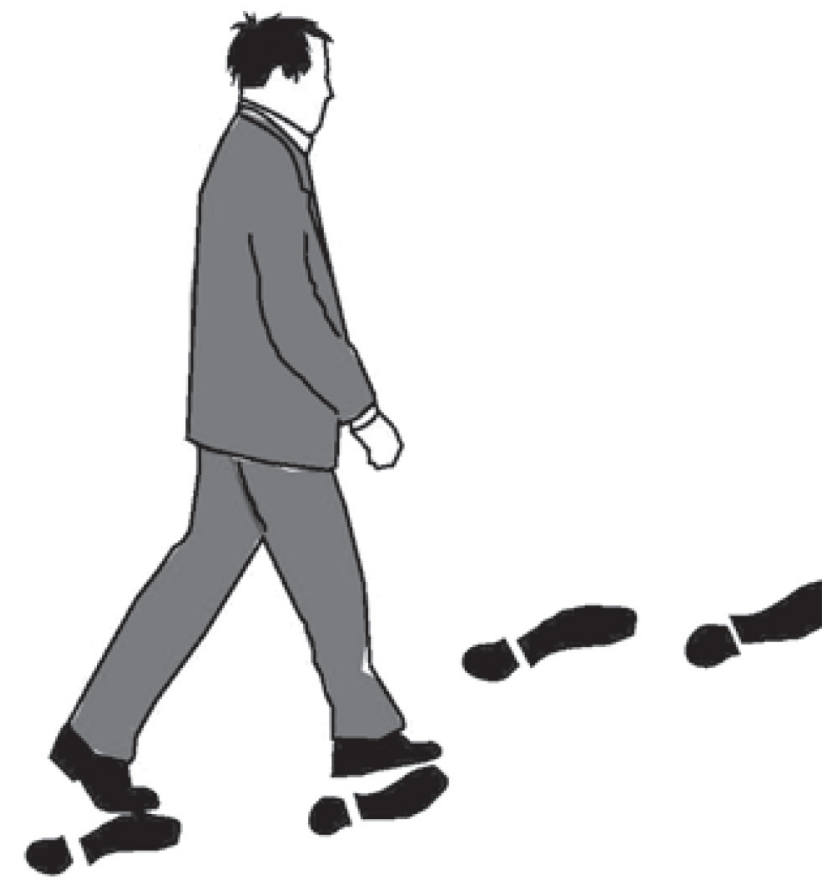

Figure 1. Picture-metaphor matching task: "He is following in his father's footsteps."

word, e.g. "The cross is below the heart". To facilitate the task and avoid interference with possible reading difficulties, the experimenter read the written word.

Experiment 3 tested participants' ability to produce spatial prepositions in simple non-figurative sentences, consisting of a noun expressing the role of subject, verb, and prepositional phrase indicating a spatial relation. In this sentence-completion task (e.g. He is sitting ... the chair.), which requires comprehension of spatial prepositions for accurate completion, the stimuli consisted of 20 sentences. Examples of spatial prepositions that were required to correctly complete the sentences included: in, on, below, on top of, in front of, among others. The experimenter read each sentence making a pause for a missing preposition. The task was to say which preposition was missing, after the sentence was read.

Experiment 4 tested participants' comprehension of sentences with spatial metaphors. In this picture-metaphor matching task, 14 pairs of drawings were created for a selection of 14 sentential spatial metaphors, such as $\mathrm{He}$ is following in his father's footsteps. Crucially, one drawing depicted the literal meaning and the other drawing depicted the figurative meaning of the sentence (Figure 1). The two drawings of each pair were equal in size and positioned next to each other, with the metaphorical sentence written above them. The experimenter read the sentence. The task was to decide which drawing was a better match for the sentence. The drawings depicting literal and metaphoric meanings were presented on the left vs. right side equal number of times, in a randomized order.
Before each experiment, the patient completed two to four practice trials to demonstrate that he understood the task. The time to respond was not limited in any of the experiments. The patient was tested in a quiet room at his home, in a single session. The study took about 2 hours to complete.
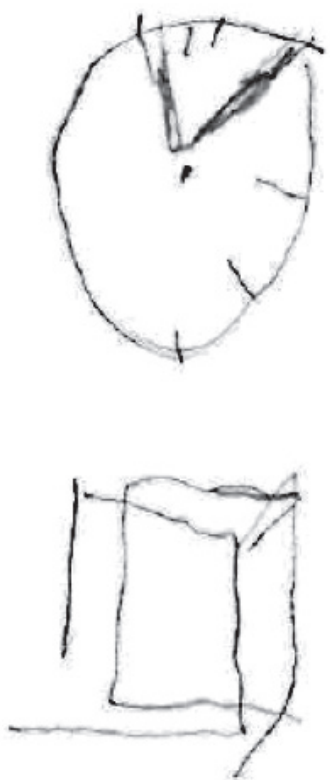

Figure 2. ZG's drawing of a clock face from memory (above) and his copy of a cube (below). 


\section{RESULTS}

Evaluative measures. ZG achieved maximum scores on all subtests of the aphasia screening test, except for reading, where he failed to read the first two letters in $50 \%$ of words and was not able to correctly read sentences. It is likely that the reading difficulty was due to spatial neglect and that correctly reading half of the words stimuli involved a strategy of relying on lexical knowledge, which overruled the effects of neglect on perception of letters (20). This strategy was clearly ineffective in reading sentences.

ZG's score on MoCA was 20/30, revealing difficulties in visuo-spatial, executive, and memory subtests. Figure 2 illustrates lack of detail, consistent with spatial neglect, on the left side of ZG's copy of the cube and especially on the clock drawing, which has correct time setting but contains visuo-spatial errors.

ZG's score on the verbal working memory test was 9/20. The results of this test show that he was able to remember the names of three to four months long enough to correctly report which months appeared in a particular string, but he was not able to reorder them canonically before reporting them back, as required by the task, except in the sequences consisting of two and three months. This indicates a limitation of verbal working memory capacity (18).

Finally, ZG scored 24/36 on Raven's Progressive Color Matrices, achieving $6 / 12$ on component A, $7 / 12$ on component $A_{B}$ and $11 / 12$ on component $B$. The tasks in these components differ in the sense that some may be solved by relying purely on visual-pattern matching skills, whereas others require relational reasoning (21), which is more relevant for language processing (7). ZG's scores on this test indicate that his visual-pattern matching abilities are impaired, as also indicated by the subtests of MoCA, whereas his relational reasoning is well-preserved.

Experimental measures. ZG demonstrated good comprehension of spatial metaphors (13/14; 92.8\%) and basic spatial relations $(14 / 14 ; 100 \%)$. The modified $t$ test, designed for comparing an individual case to a small control sample (22), revealed no statistically significant differences between ZG's performance and the control group's performance on the test of spatial metaphors ( $p=0.08$, one-tailed) and spatial relations ( $p$ $=0.35$, one-tailed). However, ZG's use of spatial prepositions in literal sentences and his score on the spatial working memory test were considerably different from the scores of the control group (spatial prepositions: $p$ $=0.006$, one-tailed; spatial working memory: $p<0.005$, one-tailed).

\section{DISCUSSION}

The main finding of our study is that the comprehension of familiar sentence-level metaphors with spatial terms is preserved in the presently studied patient, in whom stroke affected the right temporo-parietal region. This finding is consistent with the view that the left hemisphere may support comprehension of familiar sentence-level metaphors either by default or by compensation when the right hemisphere is injured.

ZG's performance pattern does not resemble the pattern of sentence-level metaphor comprehension in $\mathrm{RH}$ damaged patients found by Winner \& Gardner (1977), i.e. impairment in picture-metaphor matching. ZG's metaphor comprehension is also unlike the comprehension pattern of Van Lancker and Kempler's (13) RH-damaged patients, who could not comprehend familiar phrases. Finally, ZG's clinical profile is very similar to the profile of patient 444DX from the Ianni et al. (14) study: they both have $\mathrm{RH}$ damage, normal language, but compromised memory, executive function and visuo-spatial abilities. Yet, they exhibit different metaphor comprehension patterns: 444DX could not comprehend moderately familiar sentence-level metaphors and literal sentences, which indicates a general sentence level impairment. In contrast, ZG's comprehension of metaphoric sentences was good relative to the control group.

Furthermore, ZG comprehended well object-toobject spatial relations. Since there were only two objects per trial in this task, there was no "clutter" in the scene, a factor that is disruptive to spatial processing in patients with neglect (23). Although both neglect and hemianopia are common following $\mathrm{RH}$ damage, there are important differences between the two conditions. Briefly, hemianopia or visual field deficit is a sensory loss caused by damage to the primary visual pathways running between the optic tract and striate cortex, whereas neglect refers to inability to attend to contralesional space, due to cortical lesion $(24,25)$. Crucially, while the boundary between the intact and blind field in hemianopia is typically perceived as a "cliff", the visual loss in neglect is more gradual and the size of the neglected field appears to depend on the features of the scene (26).

An alternative explanation of ZG's comprehension of object-to-object spatial relations is grounded in recent fMRI findings from healthy adults, which point to a bilateral fronto-parietal network supporting both allocentric and egocentric frames of reference, with the former being more associated with activation in the right parietal lobe, in addition to the bilateral ventrolateral occipito-temporal cortex and the bilateral hippocampal formation (4). If the network of areas that supports allocentric representations is much wider than the right parietal region, functional compensation might have been mediated by these additional areas, resulting in ZG's good performance on this task. Thus, our data is aligned with the network approach to spatial processing, according to which lesions to only posterior parietal region of the right hemisphere cause mild spatial neglect that may not be apparent in spontaneous behavior (2). The network approach to complex functions such as directed attention, memory and 
language offers a more plausible explanation of cognitive deficits caused by a stroke than the approach that seeks to determine one-to-one brain-function mapping. One reason is that stroke lesions are typically large, affecting more than one brain area and often spreading subcortically to deep grey matter and white matter.

Our findings are also compatible with a model according to which the right temporal lobe and basal ganglia injury contribute to chronic spatial neglect (27), because both regions were affected in ZG. The model further postulates damage to specific white matter (WM) tracts in relation to spatial neglect. In the absence of data on WM for the present study, we cannot speak of whether WM lesion contributed to ZG's condition, but the possibility remains that in addition to the cortical and subcortical grey matter lesions, white matter was also damaged. The most probable candidate tract would be the superior longitudinal fasciculus (SLF), more specifically (parietal portion of) segment II, which connects inferior parietal and prefrontal regions (28). Damage to this specific tract has been associated with spatial neglect (29). Furthermore, lack of cortical damage to the left prefrontal areas that support working memory cannot explain ZG's poor performance on spatial and verbal working memory tests. However, abnormal functional and/or structural connectivity within the fronto-parietal network is likely to contribute to these deficits, despite the cortical remoteness of intact prefrontal areas from the lesion areas. This explanation gains plausibility in the context of recent fMRI and repetitive transcranial magnetic stimulation findings that implicate Brodmann area 6-which is one of termination loci of SLF segment II-in updating verbal (medial BA 6) and spatial representations (lateral BA 6 in both hemispheres) (30). It appears then that possible damage to this tract could explain ZG's working memory problems, both spatial and semantic, which raises intriguing questions on lateralization of the neural substrates for verbal and spatial working memory.

One limitation of the present study is related to the fact that the patient did not undergo scanning immediately prior to his taking part in the present study and therefore we cannot fully exclude the possibility pointed out by an anonymous reviewer that other ischemic strokes might have taken place during the time preceding the actual study. However, the neurological follow-ups and patient's once-a-month visits to the general practitioner provide no evidence for further deterioration of his cognitive functions.

\section{CONCLUDING REMARKS}

In conclusion, we studied comprehension of spatial metaphors in a right-handed patient who had previously suffered a RH stroke in temporo-parietal region. We found that his comprehension of spatial metaphors was intact as well as his comprehension of spatial relations in the allocentric frame of reference. However, his spatial working memory was less preserved, even though it did not affect his performance on the type of spatial tasks used in the present study. This deficit may have a bigger impact on more complex spatial tasks, in which several spatial variables need to be stored and manipulated at the same time, or on visuo-spatial search of "cluttered" scenes that requires the ability to keep track of already searched points, which is difficult for patients with spatial neglect. Regardless, our study provides further evidence for the link between spatial working memory deficit and spatial neglect (23).

Finally, our data indicate that heterogeneity in behavioral output after RH stroke may be explained by the differences in the degree of damage to the network regions and their connections. Future studies will investigate how focal and diffuse lesions in the relevant networks contribute to dysfunction of spatial language, testing hypotheses on the role of spatial working memory in linking the domains of space and language.

\section{REFERENCES}

1. Kerbler, G.M., Nedelska, Z., Fripp, J., Laczo, J.Vyhnalek, M., Lisy, J. et al. (2015). Basal forebrain atrophy contributes to allocentric navigation impairment in Alzheimer's disease patients. Frontiers in Aging Neuroscience, 7, 185.

2. Mesulam, M.M. (1981). A cortical network for directed attention and unilateral neglect. Ann. Neurol. 10, 309-325.

3. Mesulam, M.M. (1999). Spatial attention and neglect: parietal, frontal and cingulate contributions to the mental representation and attentional targeting of salient extrapersonal events. Phil. Trans. R. Soc. Lond. B, 354, 1325-1346.

4. Zaehle, T., Jordan, K., Wuestenberg, T., Baudewig, J., Dechent, P. \& Mast, F.W. (2007). The neural basis of the egocentric and allocentric spatial frame reference. Brain Research, 1137, 92-103.

5. Chatterjee, A. (2001). Language and space: some interactions. TRENDS in Cognitive Sciences, 5, 55-61.

6. Chatterjee, A. (2008). The neural organization of spatial thought and language. Sem. Speech Lang., 29, 226-238.

7. Wu, D.H., S. Waller, \& A. Chatterjee. (2007). The functional neuroanatomy of thematic role and locative relational knowledge. J. Cogn. Neurosci., 19, 1542-55.

8. Wallentin, M., Ostergaard, S., Lund, E.T., Ostergaard, S. \& Roepstorff, A. (2005). Concrete spatial language: see what I mean? Brain \& Language, 92, 221-233.

9. Bottini, G., Corcoran, R., Sterzi, R., Paulesu, E., Schenone, P, Scarpa, R.S. et al. (1994). The role of the right hemisphere in the interpretation of figurative aspects of language. Brain, 117, 1241-1253.

10. Schmidt, G.L., DeBuse, C.J. \& Seger, C.A. (2007). Right hemisphere metaphor processing? Characterizing the lateralization of semantic processes. Brain \& Language, $100,127-141$. 
11. Rapp, A.M., Leube, D.T., Erb, M., Grodd, W. \& Kircher, T.T.J. (2007). Laterality in metaphor processing: lack of evidence from functional magnetic responance imaging for the right heipshere theorey. Brain \& Language, 100, 142-149.

12. Winner, E. \& Gardner, H. (1977). The comprehension of metaphors in brain damaged patients. Brain, 100, 717-729.

13. Van Lancker, D.R. \& Kempler, D. (1987). Comprehension of familiar phrases by left- but not by righthemisphere damaged patients. Brain \& Language, 32, 265-277.

14. Ianni, R.G., Cardillo, E.R., McQuire, M. \& Chatterjee, A. (2014). Flying under the radar: figurative language impairments in focal lesion patients. Frontiers in $\mathrm{Hu}$ man Neuroscience, 8,871 .

15. Casasanto, D. \& Bottini, R. (2013). Spatial language and abstract concepts. WIREs Cognitive Science 5, 139-149.

16. Vuković, M. (2011). Afaziologija. Beograd: Univerzitet u Beogradu - Fakultet za specijalnu edukaciju i rehabilitaciju.

17. Nasreddine, Z., Phillips, N.A., Bédirian, V., Charbonneau, S., Whitehead, V., Collin, I., Cummings, J.L. \& Chertkow, H. (2005). The Montreal Cognitive Assessment, MoCA: a brief screening tool for mild cognitive impairment. J. Am. Geriatr. Soc., 53(4), 659-699.

18. MacDonald, M.C., Almor, A., Henderson,V.W., Kempler, D. \& Andersenet, E.S. (2001). Assessing Working Memory and Language Comprehension in Alzheimer's Disease. Brain \& Language, 78, 17-42.

19. Raven, J. C., Court, J. H., \& Raven, J. (1990). Manual for Raven's progressive matrices and vocabulary scalessection 2: Coloured progressive matrices. Oxford: Oxford Psychologists Press.

20. Sieroff, E. (2015). Acquired spatial dyslexia. Annals of Physical and Rehabilitation Medicine. DOI: 10.1016/j. rehab.2015.07.
21. Baldo, J.V., Bunge, S.A., Wilson, S.M. \& Dronkers, N.F. (2010). Is relational reasoning dependent on language? A voxel-based symptom mapping study. Brain \& Language, 113, 59-64.

22. Crawford, J.R. \& Howell, D.C. (1998). Comparing an individual's test score against norms derived from small samples. The Clinical Neuropsychologist, 12, 482-486.

23. Driver, J. \& Husain, M. (2002). The role of spatial working memory deficits in [pathological search by neglect patients. In: Karanth, H.O., Milner, D. \& Vallar, G. (Eds.), The cognitive and neural bases of spatial neglect. Oxford: Oxford University Press (pp. 351-362).

24. Halligan, P.W. (1999). Hemianopia and visual neglect: a question of balance. J Neurol Neurosurg Psychiatry 67, 561-566.

25. Ting D.S., Pollock, A., Dutton, G.N., Doubal, F.N., Thompson, M., Dhillon B. et al. (2011) Visual neglect following stroke: current concepts and future focus. Surv Ophthalmol 56, 114-134.

26. Gallagher, M., Wilkinson, D.T. \& Sakel, M. (2013) Hemispatial neglect: clinical features, assessment and treatment. British Journal of Neuroscience Nursing 9, 273-277.

27. Karnath, H.O., Rennig, J., Johannsen, L. \& Rorden, C. (2011). The anatomy underlying acute vs. chronic spatial neglect: a longitudinal study. Brain, 134, 903-912.

28. Makris, N., Kennedy, D.N., McInerney, S., Sorensen, G.A., Wang, R., Caviness, V.S. et al. (2005). Segmentation of Subcomponents within the Superior Longitudinal Fascicle in Humans: A Quantitative, In Vivo, DTMRI Study. Cerebral Cortex, 15:854-869.

29. Thiebaut de Schotten, M., Urbanski, M., Duffau, H., Vollem E., Levym R., et al. (2005). Direct evidence for a parietal-frontal pathway subserving spatial awareness in humans. Science, 309, 2226-2228.

30. Tanaka, S., Honda, M. \& Sadato, N. (2005). Modalityspecific cognitive function of medial and lateral human Brodmann area 6. The Journal of Neuroscience, $25,496-501$. 